\title{
Educational differentials in adult mortality in low- and middle-income countries
}

\author{
BRUNO MASQUELIER ${ }^{1}$ \\ ALESSANDRA GARBERO
}

\begin{abstract}
Résumé
Dans les pays à haut revenu, il a été amplement démontré que la mortalité des adultes est plus faible au sein des catégories professionnelles favorisées ainsi que chez les personnes bénéficiant d'un niveau d'instruction élevé ou d'un revenu confortable. Dans les pays à revenu faible ou intermédiaire, les différentiels de mortalité aux âges adultes sont par contre nettement moins bien étudiés en raison du manque d'information sur les caractéristiques socio-économiques des personnes décédées. Cet article vise à évaluer si les informations fournies dans des enquêtes sur la survie des sœurs peuvent aider à combler cette lacune. Puisque les niveaux $d^{\prime}$ 'instruction sont très corrélés au sein des familles, les niveaux atteints par les femmes enquêtées peuvent servir à approximer le niveau d'instruction de leurs sœurs. Afin de quantifier les différences de mortalité, nous combinons toutes les Enquêtes Démographiques et de Santé dans un même modèle linéaire généralisé à effets mixtes. Dans la plupart des enquêtes, nous observons une relation inverse entre le niveau d'instruction et la mortalité adulte, en particulier dans les zones urbaines, mais des gradients opposés sont observés dans plusieurs pays durement frappés par l'épidémie du VIH/sida. L'hypothèse selon laquelle les femmes moins instruites auraient tendance à omettre disproportionnellement certains décès de leurs sœurs n'est pas vérifiée dans les données. Les données sur la survie des soeurs semblent plutôt bien refléter la complexité de la relation entre mortalité et éducation des adultes, en particulier dans les pays touchés par l'épidémie du SIDA. Dans l'ensemble, le recours à ces données ouvre de nouvelles voies pour mesurer les inégalités de mortalité aux âges adultes dans les pays à revenu faible ou intermédiaire.
\end{abstract}

\section{Mots-clés}

Inégalités de mortalité, mortalité adulte, frères et sœurs, niveau d'instruction, enquêtes démographiques et de santé.

1. Centre de recherches en démographie, Université catholique de Louvain, Belgium.

2. International Fund for Agricultural Development, Rome, Italy. 


\begin{abstract}
In high-income countries, there is extensive evidence showing that higher levels of educational attainment, higher income and higher occupational classes are correlated with lower mortality rates among adults. In low- and middle-income countries, far less is known on mortality differentials in this age group due to the lack of information on the socio-economic characteristics of the deceased. In this paper, we evaluate whether survey reports on the survival of sisters can help to fill this gap. We find that levels of educational attainment are correlated within families, and therefore characteristics of the deceased can be inferred from levels attained by their sisters responding to the survey. Because estimates based on sibling survival histories have large confidence intervals, we pool all Demographic and Health Surveys together and apply a generalized linear mixed-effects model to capture mortality differentials. In most surveys, higher education is indeed associated with lower risks of dying, especially in urban areas, but reverse gradients are observed in several countries experiencing generalized HIV epidemics. There is limited support for the hypothesis that women with less education are disproportionately omitting to report some deaths. Instead, we argue that sibling histories truly reflect the complexity of the relationship between adult mortality and education, especially in countries affected by the HIV/AIDS epidemic. Overall, the sibling approach offers new avenues for measuring inequalities in adult mortality in low- and middleincome countries.
\end{abstract}

\title{
Keywords
}

Inequalities in mortality, adult mortality, siblings, educational attainment, demographic and health surveys.

The existence of an education gradient in adult mortality in high-income countries has been widely documented in the literature (Kitagawa, Hauser, 1973; Kunst, Mackenbach, 1994; Preston, Elo, 1995; Zajacova, 2006; K. C., Lentzner, 2010; Hummer, Lariscy, 2011). The gradient has widened in recent decades in the Russian Federation, Western Europe and the United States, and this adverse trend has rekindled interest in inequalities in mortality (Mackenbach et al., 2003; Murphy et al., 2006; Meara et al., 2008). By contrast, far less is known on inequalities in adult mortality in low- and middle-income countries due to education, income or occupation. Maternal education has been established as the single most important determinant of differences in child survival (Caldwell, 1979; Fuchs et al., 2010), but there is limited evidence of the persistence of these differentials in adulthood. Some studies conducted in Asia document the usual negative relationship between education and adult mortality, with a few exceptions that are primarily related to deaths due to breast cancer or ischemic heart disease (Samir, Lentzner, 2010). In 
sub-Saharan Africa, comparable studies on mortality differentials remain rare (Berhane et al., 2002) and results on morbidity gradients are more mixed, especially as far as the link between HIV infection and educational attainment is concerned (Fortson, 2008).

This lack of conclusive research is mainly due to the incompleteness of vital registration systems, which makes it difficult to estimate even the overall level of mortality in many low- and middle-income countries (Mathers et al., 2005). Measuring differentials is further complicated by the quasi absence of questions on the socio-economic characteristics of the deceased in censuses and surveys. In addition, few demographic methods developed for incomplete data lend themselves to the measurement of differentials. For example, consider intercensal survival methods, a common avenue for estimating adult mortality (Preston, Bennett, 1983). Typically, with intercensal survival methods, the number of women aged 50-54 in a census conducted in 2015 would be compared with the number of women aged 40-44 in a census conducted ten years earlier for each level of educational attainment. When reconstructing populations by age, sex and level of educational attainment since 1970, Lutz et al. (2007) used a similar following approach: they followed up women aged 40-49 across several censuses in seven developing countries and in France. They found that the life expectancy at age 15 of women with no education differed from the value for women with primary education by one year only, and the gap between women with primary education and those with secondary education was of two years on average. These estimates were later used to compute educationspecific mortality rates to develop projections of populations by level of educational attainment (Samir et al., 2010). Yet intercensal survival techniques are highly sensitive to age misreporting and to changes over time in the completeness of the enumeration (Timæus, 1991). They also require that the population is closed to migration or that age-specific rates of net migration are available for the intercensal period. All these problems introduce errors which may greatly vary with education.

Another category of methods is probably more adequate for the study of differentials. Several estimation techniques have been developed to make use of data collected on the survival of close relatives, that is, parents, spouses or siblings. For socio-economic characteristics that are highly correlated within families, the characteristics of those who provide information can serve as proxies for the characteristics of their relatives. Timæus (1984) adopted this strategy with data on the survival of parents collected in a fertility survey conducted in Lesotho (1977). He found consistent differentials by level of educational attainment: the life 
expectancies at age 15 among parents of respondents with no formal education was about six years lower than among parents of respondents with secondary or higher education. This is much larger than estimates obtained by Lutz et al. (2007) (based on different countries). However, differentials derived from orphanhood data are difficult to interpret because the parent-child correlations in educational attainment are affected by time trends, such as a rise over time in education levels. Consider a country where of the level of educational attainment has risen dramatically; the characteristics of the children could be only loosely related to the education of their parents. Because of the smaller age difference between spouses and the potential indirect effects of characteristics of spouses on mortality (Jaffe et al., 2006), data referring to the survival of first spouses could be used as well. Unfortunately, attempts to estimate mortality rates from widowhood data have been discouraging so far, especially when using men's reports (Timæus, 1987; Makinson, 1993; Bobak et al., 2002). Widowers seem to underreport previous marriages or conceal the death of their partner (Malaker, 1986). Conversely, respondents may prefer to report a deceased partner rather than a divorce when divorces are not socially accepted. In sum, data on parents or spouses are not very promising for the exploration of differentials.

There is another familial category that can be used to compute survivorship statistics: that of the siblings. More than 110 Demographic and Health Surveys (DHS) have included questions on siblings of women aged 15 to 49 since the early 1990s. These sibling histories are now central to the measurement of adult and pregnancy-related mortality in low- and middle-income countries (Rajaratnam et al., 2010; Reniers et al., 2011). In an inspiring paper entitled «The familial technique for linking maternal death with poverty», Graham et al. (2004) suggested using sibling histories to go beyond levels and trends in mortality to include inequalities in mortality. They contended that the educational level or poverty status of women interviewed in DHS can serve as proxies for their sisters' characteristics. Quite surprisingly, this familial approach has since been seldom used, except by Damien de Walque and colleagues in a series of publications. With DHS data from Cambodia and several countries in Africa, de Walque showed that educated adults were more likely to be killed in conflicts than other segments of the population (De Walque, 2005; De Walque, Filmer, 2012; De Walque, Verwimp, 2010). De Walque and Filmer (2013) also performed a systematic analysis of DHS sibling histories and presented mortality gradients by level of educational attainment and urban/rural residence. They found the expected inverse relation between adult mortality and educational attainment. They also showed that education-based gradients had 
widened over time in countries affected by HIV/AIDS, especially for males. Their results, however, were obtained by pooling together DHS surveys in models separating countries into three broad groups: (1) sub-Saharan African countries with low HIV prevalence, (2) sub-Saharan African countries with high HIV prevalence, and (3) countries in other regions. Their analysis thus masks differences in mortality gradients between countries. De Walque and Filmer (2013) concluded that «on the whole, the data do not show large gaps by urban/rural residence or by school attainment» (p. 23). This finding is somewhat at odds with other studies conducted in low- and middle-income countries in which mortality differentials by education appear to be as pronounced as in affluent societies (Berhane et al., 2002; Huong et al., 2006; Hurt et al., 2004).

The present article aims to establish whether sibling data can provide valuable insights into the direction and magnitude of inequalities in adult mortality in relation to education. The focus is put on the methodological aspects of this «familial approach» rather than on substantive conclusions. More specifically, we address four methodological questions:

- Is a woman's educational level a good proxy for those of her sisters in low- and middle-income countries?

- Can sisters' reports shed light on cross-country variations in mortality gradients by educational level?

- Is there some evidence that the quality of death reporting varies across educational categories, introducing biases in mortality differentials?

- Can DHS data support an analysis of trends in mortality gradients?

We focus on educational attainment for two reasons. First, it is a stable characteristic across the life span, and only a very small fraction of the population has not reached their highest educational level by the age of 25 in low- and middle-income countries. Therefore, when working on mortality above age 25 , we avoid problems associated with status changes that may arise in an analysis based on occupation or household economic status. Second, educational attainment is highly correlated within groups of siblings. In high-income countries, between 40 to $60 \%$ of the overall variation in years of schooling can be accounted for by factors shared by siblings (Björklund, Salvanes, 2010). Dahan and Gaviria (2001) also found high correlation of schooling outcomes among siblings in Latin America. 


\section{Sibling histories collected in DHS}

Our analysis is based on 111 standard DHS conducted in 47 low- and middle-income countries before $2015^{3}$. This study essentially covers countries in sub-Saharan Africa (82 DHS), but also includes other countries such as Brazil, Haiti, Nepal, Cambodia, Timor-Leste and Bolivia.

DHS are nationally representative surveys comprising three main questionnaires: (1) the drawing up of a list of all household members and the collection of basic information and household characteristics, (2) a detailed individual questionnaire designed for women of reproductive ages, and (3) a men's questionnaire administered in a subsample of households. From the early 1990s, a «maternal mortality» module (alternatively called the "adult mortality» module) has been included in some women's questionnaires and a few men's questionnaires. A standardized set of questions is used to elicit an exhaustive list of siblings born to the same mother. Information is collected by birth order about their gender and survival status. Current age is recorded for surviving siblings, while age at death and years since death are asked for those deceased. Direct mortality estimates can thus be obtained from sibling reports. Additional questions identify pregnancy-related deaths. At this exploratory stage of our research, the analysis is restricted to female mortality. This is because sibling histories are mainly collected from women aged 15 to 49; only a dozen surveys have included questions on siblings in the men's questionnaire. Women's reports on their brothers could be used, but inferring levels of educational attainment from respondents is more problematic for siblings of the opposite sex.

In the absence of a gold standard, it is difficult to evaluate the performance of sibling histories in estimating adult mortality. A handful of studies compared them with estimates from the United Nations (Gakidou et al., 2004; Stanton et al., 2000; Masquelier et al., 2014). They all conclude that DHS data tend to underestimate mortality because deceased siblings are disproportionately omitted and some deceased siblings are reported as alive. In a validation study of DHS in Senegal, nearly

3. We discarded several DHS: (1) DHS Nigeria 1999, because the data are known to be of poor quality (Pullum, 2008); (2) DHS São Tomé and Príncipe 2008/9, because the sample size is too small to produce reliable estimates; and (3) DHS Mozambique 1997, because the percentage of deceased siblings with missing or unknown age at death was as high as $24 \%$ and the percentage of deceased siblings with unknown or missing information on the timing of deaths was as high as 59\%. In addition, we discarded four DHS with sibling data that are not distributed in the public domain (Eritrea, 1995; Guinea, 1992; Mauritania, 2000/1; South Africa, 2003). 
$25 \%$ of female respondents did not report the death of at least one of their adult sisters (Helleringer et al., 2014). Other data quality assessments are provided by Stanton et al. (2000) and Masquelier (2013). Moultrie et al. (2013) also discuss some limitations of sibling histories. Despite these limitations, sibling histories are widely used to generate global estimates of all-cause and maternal mortality. They are also one of the few available options for exploring mortality differentials in adult survival in countries without comprehensive registration of deaths.

\section{Is a woman's educational level a good proxy for those of her sisters?}

Our first question is whether the level of education of a respondent may be used as a proxy for that of her sisters. Ideally, we should match adult sisters together (across households) and compare their levels of educational attainment. This is impossible because many sisters of the respondent do not live in the same household, and even those who do are not easily identified in the DHS questionnaire. Kinship ties can only be established through the relationship with the household head, or, for children aged less than 15 (sometimes 18), through the identification number of their mother and father, if they live in the same household. Therefore, there is very limited information in DHS to link together adult sisters who have completed their education.

We address this issue by focusing on women reported as daughters of the household head. For each household counting at least two of these (above age 18), we randomly select a pair of sisters and compare their level of education. In accordance with the classification used in DHS, educational attainment is recoded into three categories: (1) no education, (2) primary education, and (3) lower secondary education or higher. We first compute the proportion of women who are classified in the correct category if the level attained by her sister is used as a proxy for her own. On average, $70 \%$ of women are correctly classified when using data from one of her sisters. This proportion will obviously be higher in settings with small inequalities in educational attainment, so we also compute a weighted Kappa coefficient to take into account the agreement occurring solely by chance. In $10 \%$ of surveys, there is only fair agreement on the educational attainment of two randomly selected sisters ( $<=0.4)$; in $46 \%$, moderate agreement (0.41-0.6); in $42 \%$, substantial agreement (0.61-0.8); and in two surveys, almost perfect agreement. 
The scope of mismatching is probably larger because we retained daughters of household heads who cohabit with each other, which is a more homogeneous sample than all sisters. Yet, in the absence of direct measurements, it seems reasonable to use the respondent's educational attainment as a proxy for that of her sisters. Random misclassification will dilute the mortality gradients because the different groups will be more similar to each other than in the absence of misclassification. In other words, sibling survival histories can only provide lower bounds of the mortality differentials. Wide age ranges between sisters will also compromise the quality of the approximation because older respondents are likely to be less educated than their younger sisters. The reverse is true for younger respondents compared with their older sisters. Ideally, the distribution of age differences should be symmetrical, centered around zero, and as narrow as possible. For this reason, we discard deaths and exposure time below age 25 and above age 40 for the remainder of the analysis 4 .

\section{Can sisters' reports shed light on cross-country variations in mortality gradients?}

We now turn to mortality gradients associated with education. To compute mortality rate ratios, the original datasets, which have one row for each respondent aged 15-49, are reshaped so that the total number of deaths and person-years of exposure time among sisters can be computed for the period 0-6 years prior to the survey (data for periods in the more distant past are discarded for reasons explained below). This procedure is described in detail in Moultrie et al. (2013). After the person-years and deaths have been aggregated across surveys and weighted according to the sample weights, a regression analysis can smooth mortality rates. Various strategies have been employed in previous work, including logistic regression (Obermeyer et al., 2010), Poisson regression (Timæus, Jasseh, 2004) and generalized additive models (Masquelier et al., 2014). However, all these approaches were designed to capture mortality trends at the national level, and our objective here

4. No restriction is imposed on the respondents, however. This is because women aged 25-29 should also be reported by younger sisters aged 15-24 in order to avoid a negative skew in age differences. Conversely, women aged 35-39 should also be reported by older sisters. 
is to quantify the variation between surveys in the effect of education on adult mortality.

We use a Poisson mixed-effects model, which incorporates both fixedeffects parameters and random effects associated with each survey in the linear predictor. An unpooled regression would produce noisy estimates with large confidence intervals; in contrast, this model will «shrink» the estimates toward the overall mean, especially where the sample size of a survey is small. Another way to put it is to say that surveys will «borrow strength» from each other. To simplify the analysis, we only compare women whose sisters had no education or had only reached primary school with women whose sisters had been to secondary school or higher. The coefficient associated with the educational level among the fixed effects, once exponentiated, corresponds to the overall mortality rate ratio (the overall effect of education). Among the fixed effects, the regression model also includes the log of exposure time as an offset parameter and the age group of sisters. The level and age pattern of mortality are assumed to remain constant over the 0-6-year period. The random effects consist of a survey intercept and a varying slope for the educational level of respondents. This varying slope captures variations across surveys in mortality gradients. Because residents from urban areas have higher educational attainment and the effect of education on adult survival could differ across type of residence, we also stratify the regression by the urban/rural status of the respondents. The model is fitted with the lme4 package of the statistical software R (www. r-project.org).

This model reveals several general patterns. First, in both rural and urban areas, the overall mortality rate ratio for educational level is lower than 1 (estimated respectively at 0.89 and 0.82 ) and both coefficients are significantly different from unity at the 0.05 level. As expected, this indicates that women with a higher educational level face lower risks of dying overall. Second, the mortality advantage for women with higher education is larger in urban areas, presumably because of greater disparities in access to health care. In other words, more-educated women may be better able to take advantage of health services available in urban areas. Third, there is substantial variation in mortality rate ratios. 
FIGURE 1 Plot of the conditional modes of the random effects (exponentiated) showing deviations from the overall mortality rate ratio associated with education
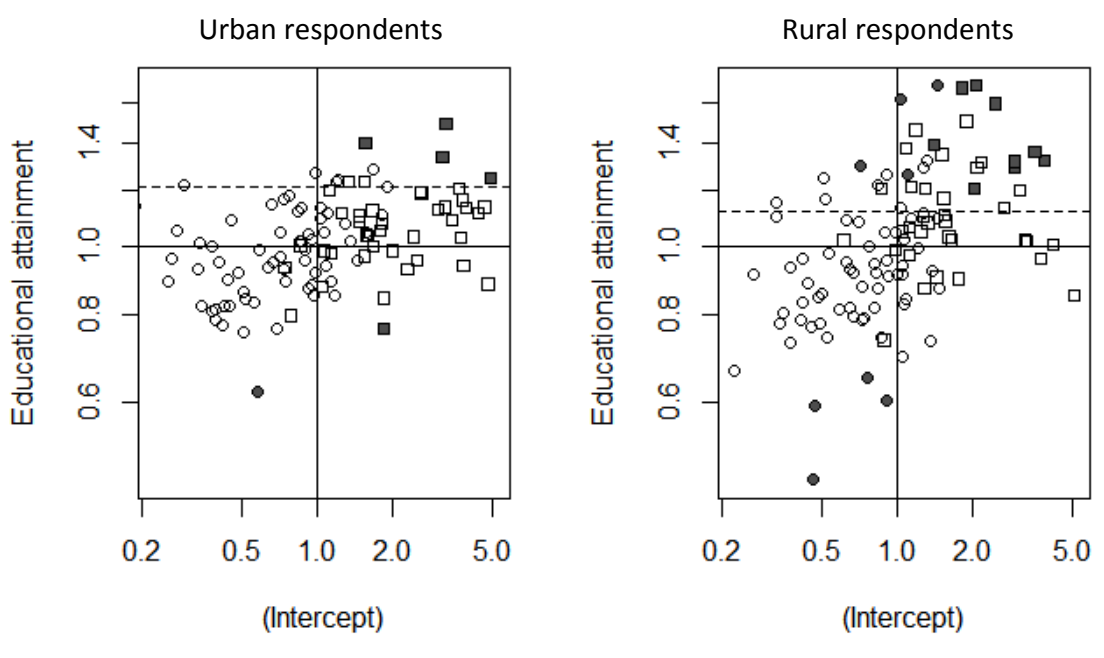

$\circ \mathrm{HN}<5 \%$ (non significant) 口 $\mathrm{HN}>5 \%$ (non significant) $\bullet \mathrm{HN}<5 \%$ (significant) $\quad$ HIV $>5 \%$ (significant)

This is illustrated in Figure 1, which plots the conditional modes of the random effects for the fitted model (these modes are exponentiated to facilitate interpretation). Values on the x-axis reflect the extent to which each survey departs from the overall mortality level. Surveys located to the right of this axis, (that is, above 1) are those where the mortality level is higher than that expected from the fixed effects. The estimated values are represented with squares if the survey was conducted in a country where HIV prevalence had reached at least 5\%, and with dots if the HIV prevalence was lower than $5 \%$ at the time of the survey (UNAIDS, 2012). The y-axis indicates how the mortality rate ratios vary across surveys. Dots presented above the horizontal axis (that is, values higher than 1) correspond to mortality rate ratios that are higher than the overall effect: they indicate that the mortality advantage of education is smaller in this particular survey. Finally, some values are located above the dashed lines: these correspond to cases where, when combining the fixed and random effects, the mortality rate ratio turns to the advantage of less-educated women (hence a reverse gradient). In addition, surveys where the mortality gradients differ significantly from the overall mortality rate ratios (as computed from prediction intervals on the random effects) are indicated with dark dots and dark squares. In urban areas, this is the case for only six surveys, four of which suggest 
that more-educated women are disadvantaged. Based on reports from rural residents, 17 surveys differ significantly from the overall mean, 13 of which are above the dashed line, indicating higher risks of dying among more-educated women. Interestingly, these surveys are almost all located in the upper half of the distribution of probabilities ${ }_{15} \mathrm{q}_{25}$, and a majority of them were conducted in countries facing high HIV prevalence, some of which are among the countries with the highest levels of HIV prevalence ever recorded in Africa: Zimbabwe, Zambia, Uganda, Malawi and Swaziland. To put it in a nutshell, we can observe distinct variations in educational differentials, but they are seldom significantly different from the overall rate ratio, and when they are, they do not all go in the expected direction.

For both urban and rural respondents, we observe significant correlations between the random effects and the HIV prevalence lagged by five years ( $\sim 0.3$ and $\sim 0.4)$ (UNAIDS 2012) as well as the overall level of mortality $(\sim 0.5)$. This confirms that the mortality advantage of education is reduced in high-mortality and high-HIV countries. It should be emphasized that in the surveys considered here, there are large differences in the share of the population which remains uneducated. One might imagine that the mortality advantage of educated women is associated with the proportion of the population that is uneducated. However, we computed Spearman's rank correlation coefficients between the percentages and the two series of rate ratios and found no significant correlations.

The comparative advantage of women whose sisters had reached secondary education meets our expectations, but the opposite pattern observed in some DHS requires further investigation. It could point to a disproportionate underreporting of deaths by women with lower education, shifting the overall rate ratio upwards. It could also point to education having a detrimental effect on the chances of survival in highmortality countries - potentially related to the HIV epidemic. We investigate this further in the following sections, taking two approaches. First, we analyze how the quality of reporting of deaths varies according to the educational attainment of respondents. Second, we evaluate how mortality gradients have changed over time in countries where several DHS have included a module on sibling survival. 


\section{Does the quality of death reporting vary across educational categories?}

Because the data used to analyze mortality gradients is retrospective, there is a concern that recall errors may be more pervasive among women with lower education. There is limited evidence with regard to this issue because previous assessments of the quality of sibling data were not disaggregated by the educational attainment of respondents. Using Pearson's chi-squared tests, we first observed that completeness of data on current age, age at death and timing of death was associated with the educational level of respondents in most surveys. However, it is unlikely that mortality differentials are heavily distorted because proportions of missing responses remain marginal. In three out of four DHS, the age at survey was reported for more than $99 \%$ of surviving sisters, the age at death was reported for more than $96 \%$ of deceased sisters, and information was available on the timing of deaths in more than $97 \%$ of cases.

FIGURE 2 Mortality rate ratios in female mortality associated

with the number of completed years prior to the survey
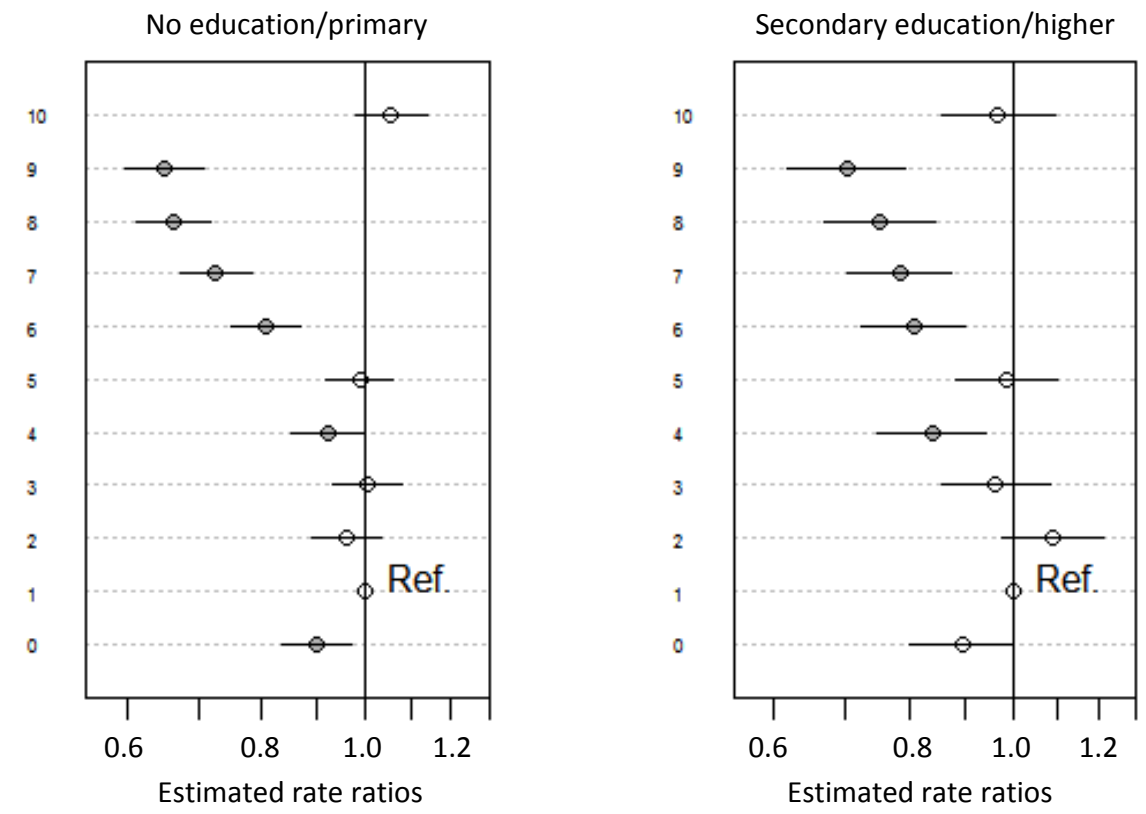

Reference category: 1 to 1.9 exact years before the survey. Estimates based on 98 DHS surveys. 
We therefore use another standard indicator of data quality - the consistency between estimates from overlapping surveys - to look into this issue. In practice, we retain only periods for which at least two surveys overlap and pool them together in one simple Poisson regression for each category of educational attainment. This corresponds to 98 surveys out of the 111 DHS analyzed in this paper (other surveys refer to countries with only one DHS with sibling histories or with DHS conducted too far apart). In addition to age, time period and country, the model also includes dummies for the time elapsed prior to the survey. The coefficients on these dummies quantify the decay in death reporting as we move further back in time. Further details on the methodology are provided in Obermeyer et al. (2010) and Masquelier et al. (2014).

Figure 2 displays rate ratios relative to time prior to the survey, for 10 completed years before data collection. This plot can be read as follows: the rate ratio for eight completed years prior to the survey is as low as 0.72 in the category "no education/primary», which means that about $30 \%$ of deaths were either unreported or displaced, compared with one to two years before the survey. Because the extent of death reporting does not vary much in the 0-6-year period, we retained only the data for that period to estimate the mortality advantage of education. Also, the pattern is analogous in both categories of educational attainment for these first few years. By contrast, the completeness of death reporting declines rapidly to below 1 as the interval between deaths and the survey increases to beyond 5 years, and the decline is slightly more rapid among women with less education. Of course, this approach only captures the underreporting relative to the period 1 to 1.9 exact years before data collection. Reports from less-educated women could be characterized by a larger underreporting of deaths unrelated to the time prior to the survey. This method also mixes omissions of siblings and displacements of deaths ${ }^{5}$. Yet, the results provide limited support for the hypothesis that non-sampling errors are more pervasive in reports from women with low education, to the extent that they could bias estimates for the first few years before the survey.

5. This can be seen with the periods 566 and 10-11 years prior to the survey, which present higher rate ratios than surrounding periods because of heaping on years since death. 


\section{Can DHS data support an analysis of trends in mortality gradients?}

Finally, we use DHS surveys to investigate changes in mortality gradients for selected countries in which several sets of sibling histories have been collected. From the Poisson mixed-effects model described in section 3, we predict for each survey the life table probability of a woman dying between ages 25 and 40 by broad level of education (no education/primary vs. secondary/higher). Again, to limit biases related to omissions of deceased siblings, we keep only the data for the first six years before data collection and assume that mortality is constant over this period. Figure 3 presents trends over time for nine countries: Cambodia, Indonesia, Cameroon, Ethiopia, Madagascar, Malawi, Namibia, Zambia and Zimbabwe. These countries were selected because they have conducted at least three DHS with a sibling module and have varying levels of mortality (note the change in the y-axis scale).

In the first four countries, we find, as expected, that more-educated women have a survival advantage. This advantage is relatively small in Indonesia (with rate ratios of around 0.8 for more-educated women). It is more pronounced and stable over time in Cambodia and Bolivia (with rate ratios around 0.6 in both cases). In Madagascar, this advantage has reduced as mortality rates have declined - except in the last survey. We find this negative relationship between education and adult mortality in many other countries with relatively low mortality and no generalized HIV epidemic, such as Peru, the Philippines, Senegal, Nepal, and the Dominican Republic.

The other five countries displayed in Figure 3 have experienced a generalized HIV epidemic. Given the mortality attributable to AIDS in these countries and the literature on the link between HIV and education, we expected that mortality gradients would follow a common pattern. Studies published on this topic prior to 1996 found either no association or a higher risk of HIV infection among the more educated, whereas more recent studies tend to find a lower risk of HIV infection among the most educated (Hargreaves et al. 2008). This is because highly educated individuals were more likely to engage in risky sexual behaviors in the beginning of the epidemic given the availability of casual sex and the means to pay for it (Gregson et al., 2001). Forston (2008) also found a robust positive education gradient in HIV infection, after controlling for a rich set of confounders and non-response bias in HIV testing, where 
adults with six years of schooling were more likely to be HIV positive than adults with no education. More recently, it seems that more-educated people have been responding more adequately to behavioral change programs (Glynn et al., 2004). As a result, we should observe a reverse gradient between education and mortality at the beginning of the epidemic, followed by a return to small mortality differentials in favor of the more educated. Looking at the country plots in Figure 3, one could argue that this pattern is observed in Cameroon, Malawi and Zimbabwe.

FIGURE 3 Trends in the life table probability of a woman dying between ages 25 and 40 by level of education
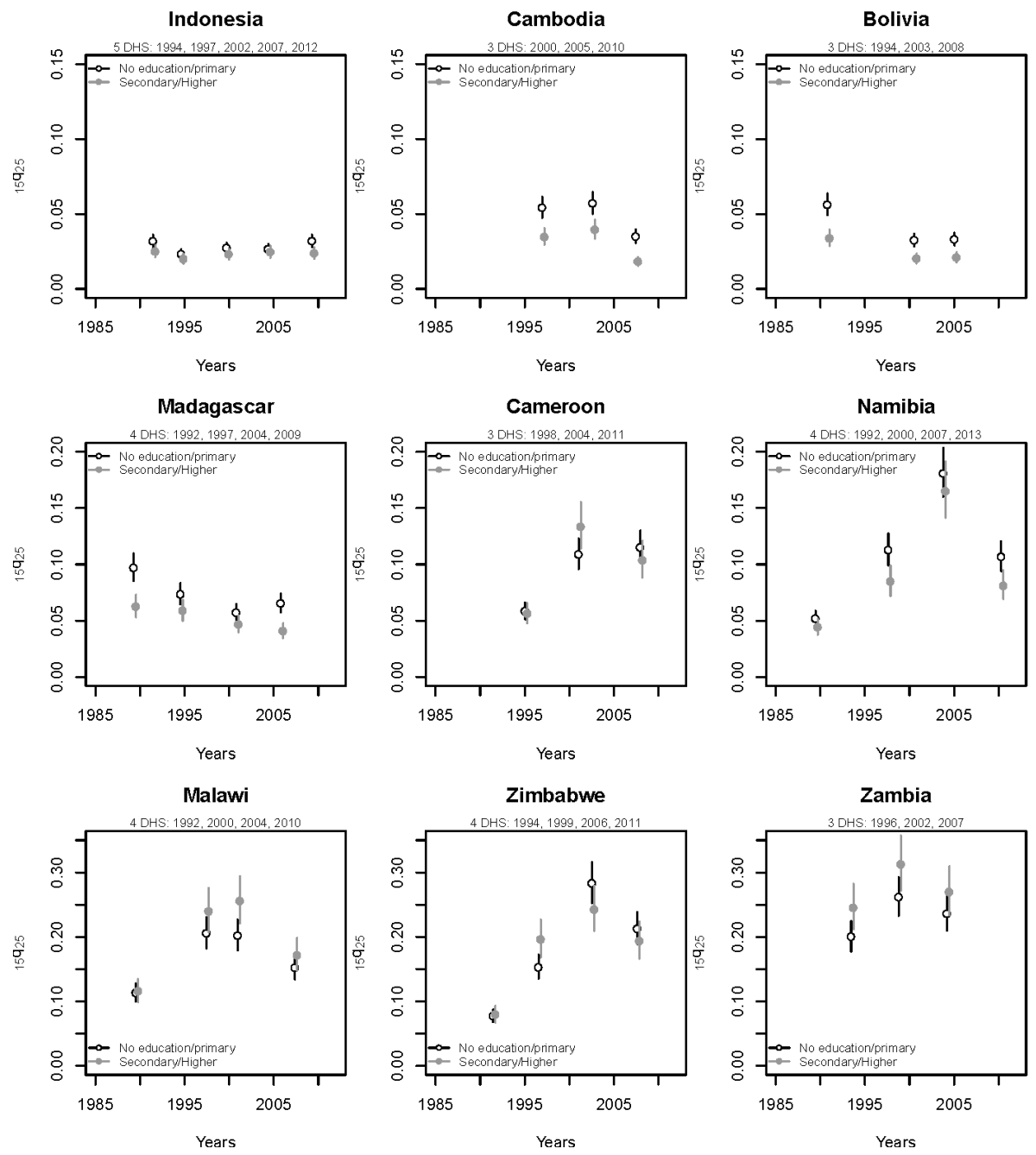
However, we also need to highlight the great variation in the magnitude of inequalities in mortality and in their direction. A more cautious conclusion is that no systematic pattern emerges clearly. For example, in Namibia, there has been a massive rise in mortality among young adults, and more-educated women have enjoyed a survival advantage throughout the period. By contrast, in Zambia, a reverse gradient is observed, with more-educated women facing relative excess risks of dying (estimated at about 1.2 over the three surveys).

\section{Discussion}

The lack of research on the span of mortality differences associated with educational level is striking in low- and middle-income countries. This is in part due to the paucity of data on adult survival, but perhaps data sources that are regularly used to estimate mortality trends should be more systematically explored for the study of health inequalities. We argue here that sibling histories can help to document empirically the relationship between educational attainment and the level of adult mortality. Because of the absence of information on the socio-economic characteristics of siblings, the critical assumption is that educational outcomes are correlated within sibships, and therefore the level of educational attainment of the respondent acts as a proxy for the level of educational attainment of her siblings. In most DHS, we have confirmed that correlations of schooling outcomes among sisters are so high that this assumption seems to hold, at least for females. Further research is needed to evaluate if the method performs well for estimating differentials in male mortality. Including a question in DHS questionnaires to link sisters living in the same household, as well as additional questions on the basic socio-economic characteristics of the siblings, would also be beneficial in order to obtain direct measurements and reduce errors of misclassification. Such errors will reduce the size of the differentials based on proxy reports, and sensitivity analyses should be undertaken to quantify their impact.

When looking at our second set of results, i.e. the ratios between the mortality rates of women whose sisters had at least reached secondary school to the rates experienced by women whose sisters were less educated, the protective effect of education is observed in a majority of surveys. However, a puzzling pattern is seen in a dozen of the surveys, where more-educated women appear to be disadvantaged, especially when analyzing reports from rural respondents. Surveys conducted in 
Cameroon, Zimbabwe, Zambia, Malawi and Uganda were characterized by the highest excess risks of dying among more-educated women. These countries have all been affected by major HIV/AIDS epidemics, albeit to a varying degree.

These reverse gradients could be attributed to several factors, such as a disproportionate underreporting of deaths by women with lower education and/or a detrimental effect of education on survival chances in high-mortality countries - with this effect largely due to the impact of the HIV/AIDS pandemic. To explore these two issues further, we measured the completeness of data on ages at death and timing of death and found an association with the respondent's level of education in many DHS, although the data remain remarkably complete in most surveys. When evaluating the consistency of mortality derived from successive surveys, we found evidence of a massive underreporting of deaths. When limiting our analysis to the 0-6-year period before the survey, there was no sign that underreporting is more pervasive among women with lower education. In sum, differentials in non-sampling errors are unlikely to be large enough to invalidate the approach.

Finally, this study presented trends in female mortality by level of educational attainment for nine countries with several DHS (Indonesia, Cambodia, Bolivia, Madagascar, Namibia, Cameroon, Malawi, Zambia and Zimbabwe). The results point to wide variations, which is a function of both the overall level of adult mortality and the stage and size of the HIV epidemic. In countries with a relatively low level of adult mortality, such as Bolivia and Madagascar, we found the expected negative gradient. Some countries presented an evolving gradient instead, which points to the dynamic and heterogeneous role of HIV as a confounding factor vis-à-vis the positive relationships between educational attainment and survival gains.

Our results need to be interpreted with caution because of four important caveats. First, confidence intervals around adult mortality estimates often overlap, despite wide gradients in mortality levels. Hence, DHS data lack statistical power and provide at best a rough estimate of the extent and direction of the observed gradients. However, sibling histories can provide a rough idea of the extent and direction of the gradients. This, in itself, is a major contribution, considering the data constraints in this area. Second, selection biases could be introduced by the retrospective collection of data, and they could affect the mortality rate ratios (Masquelier, 2013). Here, we assumed that mortality is unrelated to the number of sisters surviving in adulthood. Third, we cannot really unpack the reasons and mechanisms behind such gradients because no 
data on causes of deaths or behaviors of siblings are collected as part of existing DHS surveys. Another survey program, the World Health Survey, has included in the module on the survival of siblings questions about the circumstances of siblings' death and some symptoms, and future research could make use of such data. Fourth, the data does not allow us to establish whether these gradients are truly associated with education or whether other characteristics which are closely related to education, such as urban-rural residence and income, come into play.

Keeping these limitations in mind, the use of the sibling method represents a valid improvement over the techniques used up until now to estimate the size of mortality differences associated with education in developing countries. In particular, sibling histories could inform the reconstruction of population trends and projections by level of educational attainment (Lutz, Goujon, 2001). These analyses should at least take into account temporal changes in the relationship between education and mortality, which is conditional on context as well as patterns of causes of death. Further research should focus on validating results presented in this paper with supplementary datasets for specific countries that would allow triangulation of results. More generally, an understanding of the causal mechanisms that drive the relationship between education and mortality and lie behind such gradients is still lacking for developing countries.

\section{Acknowledgments}

This analysis was carried out thanks to a fellowship from the Belgian National Fund for Scientific Research (FNRS). We thank two reviewers for their suggestions and comments.

\section{References}

Berhane Y., Hogberg U., Byass P., Wall S. (2002), «Gender, Literacy, and Survival among Ethiopian Adults, 1987-1996», Bulletin of the World Health Organization, 80, pp. 714-20.

BJÖRKLUNd A., SAlvANES K. (2010), «Education and Family Background: Mechanisms and Policies», E. A. Hanushek, S. J. Machin, L. Woessmann (eds), Handbook of the Economics of Education, 3, Elsevier Science, pp. 201-247. 
Bobak M., Murphy M., Pikhart H., Martikainen P., Rose R., Marmot M. (2002), "Mortality Patterns in the Russian Federation: Indirect Technique Using Widowhood data", Bulletin of the World Health Organisation, 80 (11), pp. 876-81.

CALDWELl J. C. (1979), «Education as a Factor in Mortality Decline: An Examination of Nigerian Data», Population Studies, 33 (3), pp. 395-413, http://dx.doi.org/10. 2307/2173888.

DAHAN M., GAVIRIA A. (2001), "Sibling Correlations and Intergenerational Mobility in Latin America», Economic Development and Cultural Change, 49 (3), pp. 537-554, http://dx.doi.org/10.1086/452514.

De Walque D. (2005), "Selective Mortality during the Khmer Rouge Period in Cambodia», Population and Development Review, 31 (2), pp. 351-368, http://dx.doi. org/10.1111/j.1728-4457.2005.00069.x.

De Walque D., Filmer D. (2012), «The Socioeconomic Distribution of Adult Mortality during Conflicts in Africa», Peace Economics, Peace Science and Public Policy, 18, pp. 1'554-8'597.

De Walque D., Filmer D. (2013), «Trends and Socioeconomic Gradients in Adult Mortality around the Developing World", Population and Development Review, 39 (1), pp. 1-29, http://dx.doi.org/10.1111/j.1728-4457.2013.00571.x.

De Walque D., Verwimp P. (2010), "The Demographic and Socio-Economic Distribution of Excess Mortality during the 1994 Genocide in Rwanda», Journal of African Economies, 19 (2), pp. 141-162, http://dx.doi.org/10.1093/jae/ejp029.

ForTSON J. (2008), "The Gradient in Sub-Saharan Africa: Socioeconomic Status and HIV/AIDS», Demography, 45 (2), pp. 303-322, http://dx.doi.org/10.1353/dem.0. 0006.

FUCHS R., PAMUK E., LUTz W. (2010), «Education or Wealth: Which Matters more for Reducing Child Mortality in Developing Countries?», Vienna Yearbook of Population Research, 8, pp. 175-199, http://dx.doi.org/10.1553/populationyearbook2010s175.

GaKidou E., Hogan M., Lopez A. (2004), "Adult Mortality: Time for a Reappraisal», International Journal of Epidemiology, 33 (4), pp. 710-717, http://dx.doi.org/10. 1093/ije/dyh099.

Glynn J., Carael M., Buvé A., Anagonou S., Zekeng l., Kahindo M., Musonda R. (2004), «Does Increased General Schooling Protect against HIV Infection? A Study in four African Cities», Tropical Medicine \& International Health, 9 (1), pp. 4-14, http://dx.doi.org/10.1046/j.1365-3156.2003.01168.x.

Graham W., Fitzmaurice A., Bell J., Cairns J. (2004), «The Familial Technique for Linking Maternal Death with Poverty", The Lancet, 363 (9'402), pp. 23-27.

Gregson S., Waddell H., Chandiwana S. (2001), "School Education and HIV Control in Sub-Saharan Africa: From Discord to Harmony?», Journal of International Development, 13 (4), pp. 467-485, http://dx.doi.org/10.1002/jid.798. 
hargreaves J., Bonell C., Boler T., Boccia D., Birdthistle I., Fletcher A., Pronyk P., GLYNN J. (2008), "Systematic Review Exploring Time Trends in the Association between Educational Attainment and Risk of HIV Infection in Sub-Saharan Africa», AIDS, 22 (3), pp. 403-414, http://dx.doi.org/10.1097/QAD.0b013e3282f2aac3.

Helleringer S., Pison G., Masquelier B., Kanté A., Douillot l., Duthé G., Sokhna C., DelaunaY V. (2014), "Improving the Quality of Adult Mortality Data Collected in Demographic Surveys: Validation Study of a New Siblings' Survival Questionnaire in Niakhar, Senegal», PLoS Med, 11 (5), http://dx.doi.org/10.1371/journal.pmed. 1001652.

HUMmer R., LARISCY J. (2011), «Educational Attainment and Adult Mortality», R. RoGERS, E. CRIMMInS (eds), International Handbook of Adult Mortality, Springer, pp. 241-261, http://dx.doi.org/10.1007/978-90-481-9996-9_12.

huong D., Van Minh H., Janlert U., Duc Van D., Byass P. (2006), "Socio-Economic Status Inequality and Major Causes of Death in Adults: A 5-Year Follow-up Study in Rural Vietnam», Public Health, 120 (6), pp. 497-504, http://dx.doi.org/10.1016/ j.puhe.2006.03.003.

Hurt L., Ronsmans C., Saha S. (2004), "Effects of Education and other Socioeconomic Factors on Middle Age Mortality in Rural Bangladesh», Journal of Epidemiology and Community Health, 58 (4), pp. 315-320, http://dx.doi.org/10.1136/ jech.2003.007351.

Jaffe D., Eisenbach Z., Neumark Y., Manor O. (2006), "Effects of Husbands' and Wives' Education on each other's Mortality», Social Science and Medicine, 62 (8), pp. 2'014-2'023.

Kitagawa E., Hauser P. (1973), Differential Mortality in the United States: A Study in Socioeconomic Epidemiology, Cambridge, Mass., Harvard University Press, http:// dx.doi.org/10.4159/harvard.9780674188471.

Kunst A. E., Mackenbach J. P. (1994), «The Size of Mortality Differences Associated with Educational Level in Nine Industrialized Countries", American Journal of Public Health, 84 (6), pp. 932-937, http://dx.doi.org/10.2105/AJPH.84.6.932.

LuTz W., Goujon A. (2001), «The World's Changing Human Capital Stock: Multi-State Population Projections by Educational Attainment», Population and Development Review, 27 (2), pp.323-339, http://dx.doi.org/10.1111/j.1728-4457.2001. 00323.x.

LUTZ W., Goujon A., KC S., SANDERSon W. (2007), «Reconstruction of Populations by Age, Sex and Level of Educational Attainment for 120 Countries for 1970-2000», Vienna Yearbook of Population Research, 5, pp. 193-235, http://dx.doi.org/10. 1553/populationyearbook2007s193.

Mackenbach J., Bos V., Andersen O., Cardano M., Costa G., harding S., Reid A., Hemström Ö., Valkonen T., Kunst A. (2003), «Widening Socioeconomic Inequalities in Mortality in Six Western European Countries», International Journal of Epidemiology, 32 (5), pp. 830-837, http://dx.doi.org/10.1093/ije/dyg209. 
MAKInSon C. (1993), "Estimates of Adult Mortality in Burundi», Journal of Biosocial Science, 25 (02), pp. 169-186, http://dx.doi.org/10.1017/S0021932000020472.

MALAKER C. (1986), "Estimation of Adult Mortality in India: 1971-1981», Demography India, 15, pp. 126-136.

MASquelier B. (2013), «Adult Mortality from Sibling Survival Data: A Reappraisal of Selection Biases», Demography, 50 (1), pp. 207-228, http://dx.doi.org/10.1007/ s13524-012-0149-1.

Masquelier B., Reniers G., Pison G. (2014), «Divergences in Child and Adult Mortality Trends in Sub-Saharan Africa: Evidence from Survey Data on the Survival of Children and Siblings", Population Studies, 68 (2), pp. 167-177, http://dx.doi.org/ 10.1080/00324728.2013.856458.

Mathers C., Fat D., Inoue M., Rao C., Lopez A. (2005), "Counting the Dead and what they Died from: An Assessment of the Global Status of Cause of Death Data», Bulletin of the World Health Organization, 83, pp. 171-177.

Meara E. R., Richards S., Cutler D. M. (2008), "The Gap Gets Bigger: Changes in Mortality and Life Expectancy, by Education, 1981-2000», Health Affairs, 27 (2), pp. 350-360, http://dx.doi.org/10.1377/hlthaff.27.2.350.

Moultrie T., Dorrington R., Hill A., Hill K., Timaeus I., Zaba B. (2013), Tools for Demographic Estimation, IUSSP, Paris.

Murphy M., Bobak M., Nicholson A., Rose R., Marmot M. (2006), «The Widening Gap in Mortality by Educational Level in the Russian Federation, 1980-2001", American Journal of Public Health, 96 (7), pp. 1'293-1'299.

Obermeyer Z., Rajaratnam J., Park C., Gakidou E., hogan M., lopez A., Murray C. (2010), «Measuring Adult Mortality Using Sibling Survival: A New Analytical Method and New Results for 44 Countries, 1974-2006», PLoS Medicine, 7 (4), http://dx.doi. org/10.1371/journal.pmed.1000260.

Preston S., Bennett N. (1983), «A Census-Based Method for Estimating Adult Mortality», Population Studies, 37 (1), pp. 91-104, http://dx.doi.org/10.1080/00324728. 1983.10405926.

Preston S., Elo I. (1995), «Are Educational Differentials in Adult Mortality Increasing in the United States?», Journal of Aging and Health, 7, pp. 476-496, http://dx.doi. org/10.1177/089826439500700402.

Pullum T. (2008), «An Assessment of the Quality of Data on Health and Nutrition in the DHS Surveys, 1993-2003», DHS Methodological Reports, 6, Calverton, Maryland, Macro International Inc.

Rajaratnam J., Marcus J., levin-Rector A., Chalupka A., Wang H., Dwyer L., Costa M., Lopez A., MurRay C. (2010), "Worldwide Mortality in Men and Women Aged 1559 Years from 1970 to 2010: A Systematic Analysis», The Lancet, 375 (9'727), pp. 1'704-1'720. 
Reniers G., Masquelier B., Gerland P. (2011), "Adult Mortality in Africa», R. Rogers, E. CRIMmInS (eds), International Handbook of Adult Mortality, Springer, pp. 151-170, http://dx.doi.org/10.1007/978-90-481-9996-9_7.

Samir K. C., Barakat B., Goujon A., Skirbekk V., Sanderson W., Lutz W. (2010), "Projection of Populations by Level of Educational Attainment, Age, and Sex for 120 Countries for 2005-2050», Demographic Research, 22 (15), pp. 383-472.

SAMIR K. C., LeNTZNer H. (2010), "The Effect of Education on Adult Mortality and Disability: A Global Perspective», Vienna Yearbook of Population Research, 8, pp. 201-235, http://dx.doi.org/10.1553/populationyearbook2010s201.

Stanton C., Abderrahim N., Hill K. (2000), «DHS An Assessment of DHS Maternal Mortality Indicators», Studies in Family Planning, 31 (2), pp. 111-123, http://dx.doi. org/10.1111/j.1728-4465.2000.00111.x.

TIMAEU I. (1984), «Mortality in Lesotho: A study of Levels, Trends and Differentials Based on Retrospective Survey Data», WFS Scientific Reports, 59, Voorburg, International Statistical Institute.

TIMAEUS I. (1987), «Estimation of Fertility and Mortality from WFS Household Surveys", J. CLeLAND, C. ScotT (eds), The World Fertility Survey: An Assessment, Oxford University Press, pp. 93-128.

TIMAEUS I. (1991), "Measurement of Adult Mortality in Less Developed Countries: A Comparative Review», Population Index, 57 (4), pp. 552-568, http://dx.doi.org/10. 2307/3644262.

TIMAEUS I., JASSEH M. (2004), «Adult Mortality in Sub-Saharan Africa: Evidence from Demographic and Health Surveys», Demography, 41 (4), pp. 757-772, http://dx.doi. org/10.1353/dem.2004.0037.

UNAIDS (2012), Global Report. UNAIDS Report of the Global Aids Epidemic, Genève, $212 \mathrm{p}$.

ZajAcova A. (2006), "Education, Gender, and Mortality: Does Schooling Have the Same Effect on Mortality for Men and Women in the US?», Social Science and Medicine, 63 (8), pp. 2'176-2'190. 